\title{
Inflammation as a procoagulant state for thrombus manifestation in a patient with secondary dilated cardiomyopathy
}

\author{
(DAndreja Čleković- \\ Kovačić*, \\ (DRenata Ivanac \\ Janković, \\ DIvana Petrović Juren, \\ OVlasta Soukup \\ Podravec, \\ Sandra Prša, \\ OKristina Milevoj \\ Križić, \\ DIva Ladić, \\ Gabrijela Bašković
}

Bjelovar General Hospital, Bjelovar, Croatia
KEYWORDS: dilated cardiomyopathy, pneumonia, thrombus, echocardiography. CITATION: Cardiol Croat. 2019;14(9-10):245-6. | https://doi.org/10.15836/ccar2019.245

*ADDRESS FOR CORRESPONDENCE: Andreja Čleković-Kovačić, Opća bolnica Bjelovar, A. Mihanovića 8, HR-43000 Bjelovar, Croatia. / Phone: 385-43-279-181 / E-mail: kovacicandreja1@gmail.com

ORCID: Andreja Čleković-Kovačić, https://orcid.org/0000-0002-4532-3597

Renata Ivanac Janković, https://orcid.org/0000-0003-4949-3953 • Ivana Petrović Juren, https://orcid.org/0000-0002-2793-3455 Sandra Prša, https://orcid.org/0000-0001-9639-3918 • Vlasta Soukup Podravec, https://orcid.org/0000-0002-4605-0068 Kristina Milevoj Križić, https://orcid.org/0000-0003-2115-3076 • Iva Ladić, https://orcid.org/0000-0003-0124-5256

Gabrijela Bašković, https://orcid.org/0000-0002-5413-873X

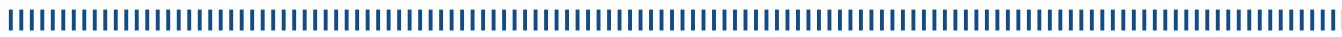

Introduction: Inflammation is the dynamic process of defense made of chronological changes which are repercussions of the body on injury or infection, It is made of complex biological and biochemical reactions which includes crucial cells of the immune system and many lots of biological mediators stimulated with mechanical injuries, toxins, infections and reaction hypersensitivity. Because of the disorders of the homeostatic system it is bigger probability of appearing thromboembolic incidence especially in patients with some disorders. Dilated cardiomyopathy is disease with structural and functional changes of heart muscle..$^{1-6}$ In the following case report the 43 -year-old male with earlier known secondary dilated cardiomyopathy who presented with a pneumonia and thrombus in left and right ventricle.

Case report: 44-year-old male patient with earlier known secondary dilated cardiomyopathy (post myocardial; from 2014) was hospitalized because of right pneumonia and heart failure. He was presented with dyspnea and chest pain and with elevated inflammation markers, D-dimer, and NT-proBNP). Because of chest pain we did the CT pulmonary angiography and we exclude pulmonary embolism. Echocardiography showed the dilatated (EDD $75 \mathrm{~mm}$ ) left ventricle (LV) with reduced EF 25-28\%. In akinetic apical part of the LV we noticed the thrombus $(7 \times 6 \mathrm{~mm}$ ) (Figure 1). The right ventricle (RV) was dilatated $(40 \mathrm{~mm})$ with reduced contractility: TAPSE $13 \mathrm{~mm}$, and RVEF around $30 \%$. In the RV we noticed thrombus (32x22 mm) (Figure 2). With the TEE we confirm the formation of the thrombus $(20 \times 30 \mathrm{~mm})$ in the apical part of the LV. With the antibiotic therapy (piperacillin with tazobactam and then with azithromycin and tetracycline and with the other medicaments) we achieve regression of pneumonia and resolution of symptoms of heart failure. In the further processing (in the tertial institution) with the cardiac magnetic resonance we prove that the formation in the left and the right heart was thrombus. The patient was prepared for heart transplantation.
RECEIVED:

August 29, 2019

ACCEPTED:

September 16, 2019

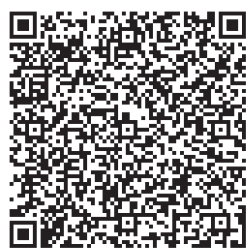

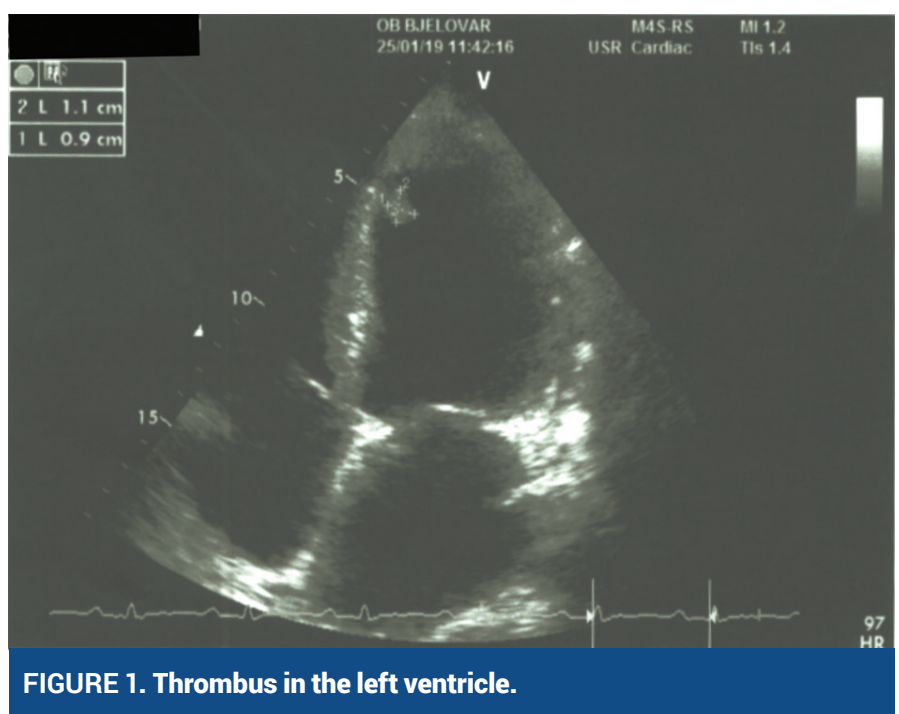

$6^{\text {th }}$ Cardiology Highlights 
Inflammation as a procoagulant state for thrombus manifestation

in a patient with secondary dilated cardiomyopathy

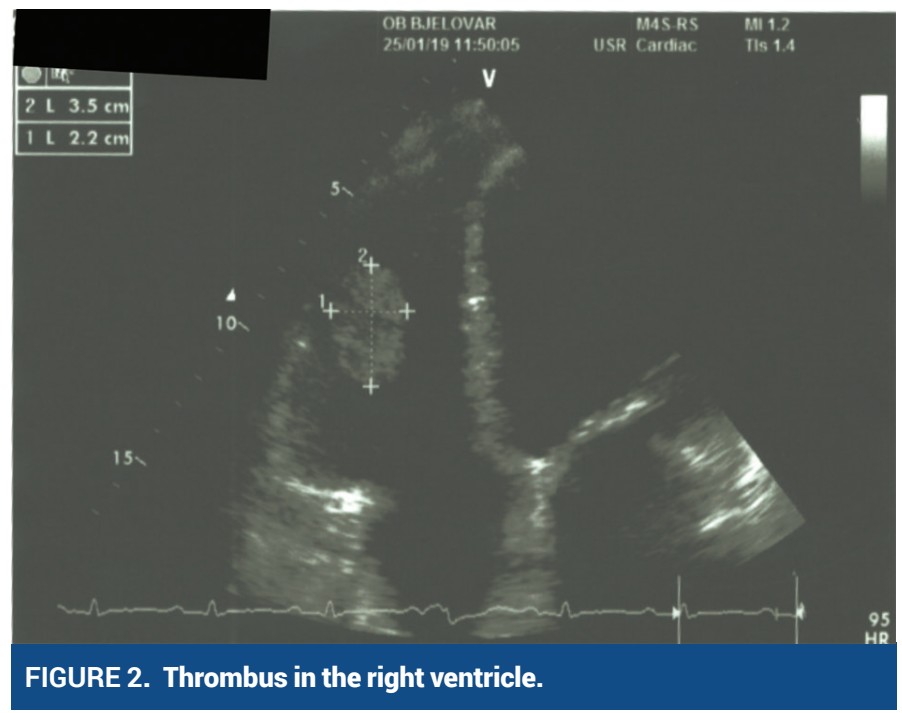

Conclusion: Every additional disease can complicate the earlier known heart disease especially with inflammation which has the procoagulant activity that encourages appearing thrombus. We must be more careful in the patient with some of the heart disease so that we do not predict it.

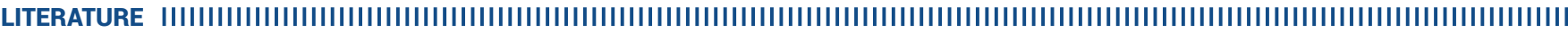

1. Alkhedaide AQ. Anti-inflammatory Effect of Juniperus Procera Extract in Rats Exposed to Streptozotocin Toxicity. Antiinflamm Antiallergy Agents Med Chem. 2019;18(1):71-79. https://doi.org/10.2174/1871523018666181126124336

2. Bendtzen K. [The immune system and inflammatory diseases]. Ugeskr Laeger. 2008 Jun 9;170(24):2110-5. PubMed: https://www.ncbi.nlm.nih.gov/pubmed/18565290

3. Herrington C, Hall PA. Molecular and cellular themes in inflammation and immunology. J Pathol. 2008 Jan;214(2):123-5. https://doi.org/10.1002/path.2303

4. Schmid-Schönbein GW, Hugli TE. A new hypothesis for microvascular inflammation in shock and multiorgan failure: self-digestion by pancreatic enzymes. Microcirculation. 2005 JanFeb;12(1):71-82. https://doi.org/10.1080/10739680590896009

5. Parker AB, Yusuf S, Naylor CD. The relevance of subgroup-specific treatment effects: the Studies Of Left Ventricular Dysfunction (SOLVD) revisited. Am Heart J. 2002 Dec;144(6):941-7. https://doi.org/10.1067/mhj.2002.126446

6. Ronco C. Cicoira M. McCullough PA. Cardiorenal syndrome type 1: pathophysiological crosstalk leading to combined heart and kidney dysfunction in the setting of acutely decompensated heart failure. J Am Coll Cardiol. 2012 Sep 18;60(12):1031-42. https://doi.org/10.1016/j.jacc.2012.01.077 